NOTE

\title{
Solar activity governs abundance of Atlantic Iberian sardine Sardina pilchardus
}

\author{
Cástor Guisande $^{1, *}$, Ana Ulla ${ }^{1}$, Peter Thejll ${ }^{2}$ \\ ${ }^{1}$ Facultad de Ciencias, Universidad de Vigo, Lagoas-Marcosende, 36200 Vigo, Spain \\ ${ }^{2}$ Climate Division, Danish Meteorological Institute, Lyngbyvej 100, 2100 Copenhagen Ø, Denmark
}

\begin{abstract}
Annual sardine Sardina pilchardus landings from 1906 to 2002 off the northwest coast of the Iberian Peninsula vary according to solar activity. When the solar cycle is short, there is a trend towards increasing water transport onshore, which favours larval retention in areas close to the coast and, hence, sardine catches increase. However, when the solar cycle is longer, the trend is toward increasing water transport offshore, carrying eggs and larvae into areas where there is not enough food to survive and, therefore, decreasing sardine catches. These findings reveal the potential importance of solar activity on all biological process affected by coastal upwelling, including pelagic fisheries.
\end{abstract}

KEY WORDS: Climate change $\cdot$ Solar activity $\cdot$ Recruitment $\cdot$ Sardine

Resale or republication not permitted without written consent of the publisher

\section{INTRODUCTION}

Solar activity is forcing long-term climate changes on earth (Eddy 1976, Siscoe 1978, Reid 1987, FriisChristensen \& Lassen 1991, Kerr 1991), but studies showing the ecological consequences of this climate change on organisms are very rare.

The number of sunspots is the most frequently used proxy for solar activity, because total solar irradiance is higher when the number of sunspots is higher (Wilson \& Hudson 1991). Furthermore, it is now well established that, statistically, changes in sunspot numbers correspond to climate changes on earth (Eddy 1976). The number of sunspots varies with a periodicity of nearly $11 \mathrm{yr}$; this cycle is called the sunspot cycle. However, because the solar magnetic fields are reversed at the peak of each approximate $11 \mathrm{yr}$ sunspot cycle, the solar activity cycle actually spans a 22 yr cycle (the Hale cycle). During the period from an odd-sunspot cycle maximum (when the number of sunspots is higher) to the next even-sunspot maximum, earth's north magnetic pole lies in the sun's southern hemisphere (negative polarity), while the opposite occurs during even-odd cycles (positive polarity). Another solar parameter showing long-term changes in solar activity is the length of the sunspot cycle, which varies with a periodicity of 80 to $90 \mathrm{yr}$ (the Gleissberg cycle). It has been shown that long-term variations in earth's temperature are closely associated with the Gleissberg cycle (Friis-Christensen \& Lassen 1991).

Year-to-year variations in recruitment success of pelagic fishes in upwelling areas are mainly governed by oceanographic factors (Cole \& McGalde 1998). In the case of the sardine Sardina pilchardus on the northwest coast of the Iberian Peninsula, watercolumn stability in February, input of nutrients in the preceding year, the winter North Atlantic Oscillation index and, particularly, larval transport offshore in March-April explain most of the year-to-year variation in sardine recruitment (Guisande et al. 2001). All these parameters affect sardine recruitment success and are, in turn, affected by climatic conditions. As mentioned above, solar activity influences earth's climate; there- 
fore, solar activity may affect recruitment success of this pelagic fish. It has been shown that the sunspot cycle introduces deterministic signals into fish catch series (Currie et al. 1993), although the physical relationship between solar activity and fish catches has not been identified so far. The aim of this study was to determine whether solar activity or the lunar cycle force the long-term changes observed in sardine landings off the northwest coast of Spain.

\section{MATERIALS AND METHODS}

Recruitment estimation. Annual juvenile landings of the Atlantic-Iberian sardine (body length between 8 and $12 \mathrm{~cm}$ ) at Vigo (northwest Spain) from 1980 to 1989 were significantly correlated with virtual population analysis recruitment estimates calibrated by acoustic surveys and the catch per unit effort of the fishery (Robles et al. 1992). Therefore, we used annual sardine juvenile landings at Vigo as a proxy for recruitment of the northwest Iberian Peninsula (Guisande et al. 2001). Data are available from 1906 to the present. Landing data were supplied by División de Operaciones Pesqueras de la Autoridad Portuaria of Vigo.

Ekman transport. Ekman transport data from 1875 to 1997 from a station located at $42^{\circ} \mathrm{N}, 10^{\circ} \mathrm{W}$ were extracted from COADS (Comprehensive Ocean Atmosphere Data Set; available at www.cdc.noaa.gov/ coads/products.html) (Woodruff et al. 1987). These data are a good indicator of oceanographic conditions in this area (Guisande et al. 2004).

The Atlantic northwest coast of the Iberian Peninsula shows a north-south orientation, and winds from the north therefore result in offshore transport. The magnitude of the offshore transport in the upper layer is considered an indicator of the amount of water upwelled along the coast into the surface layers (Mann \& Lazier 1991). Therefore, negative values of $Q_{X}$ indicate offshore water transport, whereas positive $Q_{X}$ values indicate onshore water transport. The sardine spawning season off the northwest Iberian Peninsula is from January to June, but with a higher abundance of eggs and larvae in March-April (Riveiro et al. 2000). Ekman transport in March-April $\left(Q_{X} M A\right)$ is thus an indicator of offshore larval transport.

Solar activity data. Sunspot cycle length values were taken from the web page ftp://ftp.ngdc.noaa.gov/ STP/SOLAR_DATA/SUNSPOT_NUMBERS/maxmin.new. Monthly averages of sunspot numbers were taken from the web page ftp://ftp.ngdc.noaa.gov/STP/SOLAR_ DATA/SUNSPOT_NUMBERS/MONTHLY.PLT

Statistical analysis. The significance level of correlations was determined from 5000 Monte Carlo simu- lations on surrogate data generated from either the time series of values for the solar cycle periods, or from the Ekman transport values (the results were independent of the choice). Surrogate data are generated based on scrambling of the harmonic phases. This approach preserves the important aspect of the series, which is the autocorrelative structure, and was chosen because standard statistical tests applied to autocorrelated data give incorrect results unless the tests are adapted to take the autocorrelation into account. An elegant way of doing this is to use 'suitably random' surrogate data and Monte Carlo trials to find the null hypothesis distribution of a test statistic (in our case the correlation between 2 series) and inspect this distribution for the occurrence rate of the actually observed value. In this case the null hypothesis is $H_{0}$ : no physical link between solar cycle lengths and Ekman transport values. If the observed value is rarely superseded in the random trials, then $H_{0}$ can be rejected and a statistically rare result is achieved; this is what the 'significance level' of a result should express. The autocorrelative nature of the series must be conserved, otherwise the Monte Carlo test is not valid; hence the use of the particular technique of 'scrambling harmonic phases' which gives statistically conservative results, i.e. results that do not tend to systematically overestimate the significance of results. This method has recently gained acceptance as an alternative to standard tests, and has been discussed in more detail by Thejll et al. (2003) and Gleisner \& Thejll (2003) for geophysical applications. It has been known in theoretical physics for some time (e.g. Theiler \& Prichard 1996).

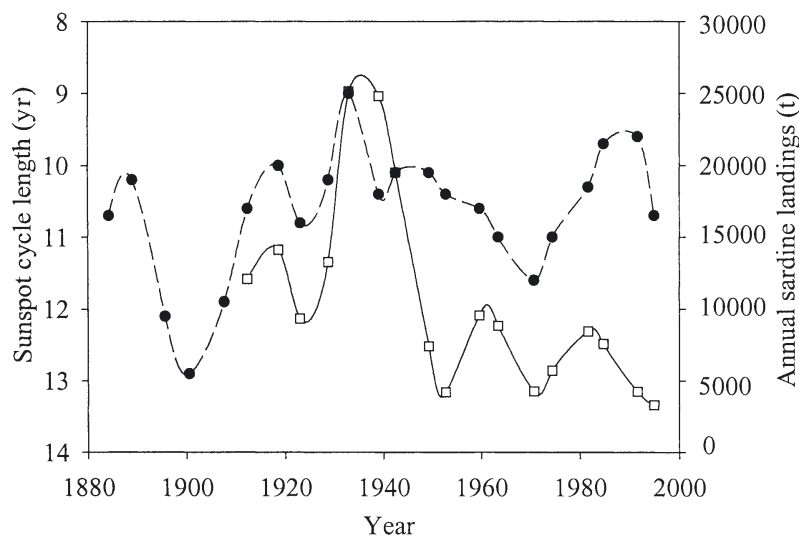

Fig. 1. Sunspot cycle length $(\bullet)$ determined as the difference between each sunspot extremum and the previous one (i.e. the difference between 2 consecutive sunspot minima, and the difference between 2 consecutive sunspot maxima), and the mean annual sardine Sardina pilchardus landings in Vigo (NW Spain) for the same period (). Cycle length and annual landings are plotted at centre of each cycle 


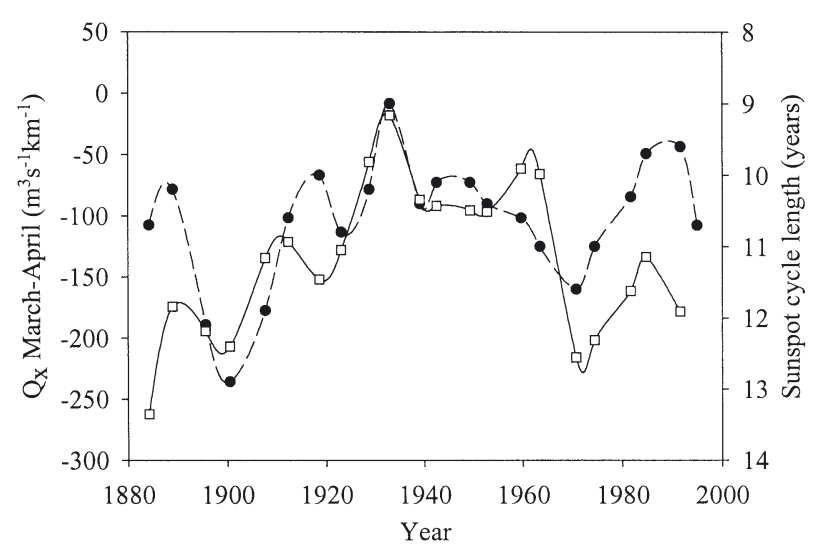

Fig. 2. Sunspot cycle length $(\bullet)$ determined as the difference between each sunspot extremum and the previous one, and the mean Ekman transport $\left(Q_{X}\right)$ in March-April at the station $\left(42^{\circ} \mathrm{N}, 10^{\circ} \mathrm{W}\right)$ off the northwest coast of the Iberian Peninsula from 1875 to 1997 (ㅁ). Cycle length and Ekman transport are plotted at centre of each cycle

\section{RESULTS}

Fig. 1 shows that the variations in solar cycle length and annual sardine catches display a similar trend. Annual sardine landings are higher when the solar cycle is shorter. The correlation between the data in Fig. 1 was calculated by correlating the points with overlapping abscissas. The Pearson correlation coefficient was 0.46 at a significance level of about $90 \%$. There is thus a $10 \%$ chance that the apparent match between the curves is a random occurrence.

This synchrony between sardine catches and solar activity is due to solar cycle length affecting the most important factor controlling recruitment in this area, $Q_{X}$ MA (Guisande et al. 2004) (Fig. 2). There is a trend toward high $Q_{X} \mathrm{MA}$ values when the solar cycle is shorter, and vice versa (Fig. 2).

Within each sunspot cycle, for both the period from a minimum to the next maximum sunspot number and the period from a maximum to the next minimum, $Q_{\mathrm{X}} \mathrm{MA}$ was higher with decreasing length of the period (Fig. 3): the correlation coefficient for the relationship between the ordinate and abscissa is about -0.56 , with a significance level of $99.3 \%$, taking serial correlation into consideration. However, the period from a sunspot maximum to the next minimum was always longer than that from a minimum to a maximum, leading to lower $Q_{X} \mathrm{MA}$ in the former (Fig. 3). Moreover, the length from the minimum to the next maximum sunspot number, when the sun's polarity was negative, was usually too long (low $Q_{X} \mathrm{MA}$ ) or too short (only a few years with high $Q_{\mathrm{X}} \mathrm{MA}$ favoured recruitment) to trigger sardine population growth. Therefore, during the period studied, sardine landings usually increased

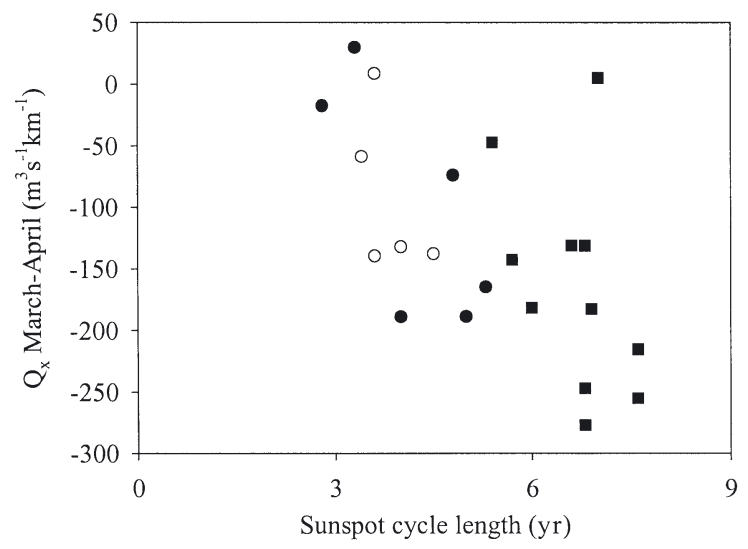

Fig. 3. Relationship between length of the sunspot cycle determined as period from a sunspot number minimum to the next maximum, when sun's polarity was positive (0) and when it was negative $(\bullet)$, and solar maximum to minimum cycle $(\square)$ plotted against mean Ekman transport $\left(Q_{X}\right)$ in March-April during same time intervals

only when the sun's polarity was positive and from the period between the minimum and the next maximum sunspot number (Fig. 4). The only exception was the significant rise in sardine landings in the 1930s (Fig. 4), which was probably due to the $Q_{X}$ MA being relatively high $\left(-78 \mathrm{~m}^{3} \mathrm{~s}^{-1} \mathrm{~km}^{-1}\right)$ during the period from the minimum to the next maximum despite the sun's negative polarity (Fig. 3).

The bi-decadal nature of the Hale cycle suggests that it is necessary to consider other bi-decadal cycles in nature, as the envelope of lunar decline is modu-

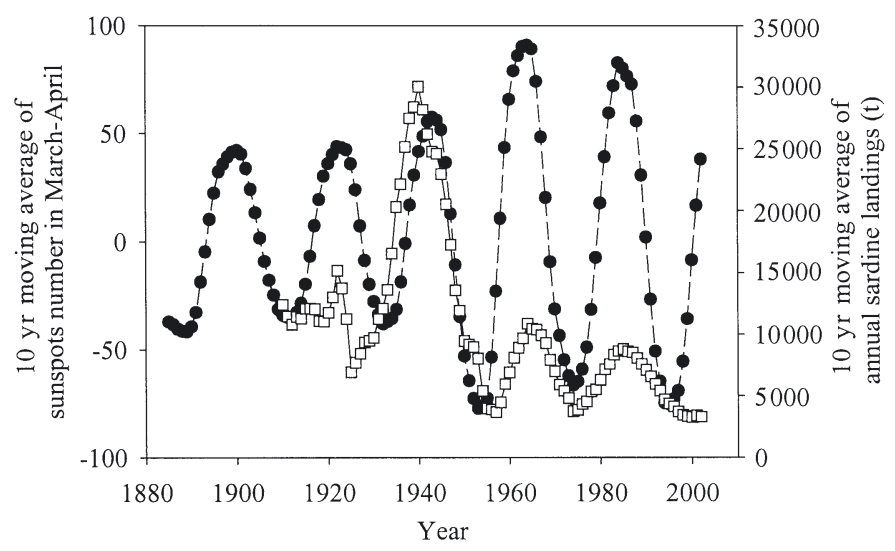

Fig. 4. Sunspot numbers and sardine Sardina pilchardus landings: 10 yr moving averages for March-April of landings in Vigo from 1906 to 2002 (ㅁ) and sunspot numbers from 1875 to 2002 $(\bullet)$. A 10 yr period was chosen to minimise effects of year-toyear variability in sardine catches. Same results are obtained when other smoothing periods are employed. For clarity, in the graphic representation of the Hale cycle, sunspots during 'even' sunspot cycles were considered negative 
lated by the 18.6 yr nodal cycle. Since lunar decline is a factor influencing terrestrial tides, we tested whether the nodal cycle correlates significantly with sardine catches and Ekman upwelling. Using the method of testing against surrogate data (see 'Materials and methods'), we found a correlation between the envelope of the nodal lunar decline time series and the Ekman transport series of -0.10 (at a $29 \%$ significance level) and between lunar decline and sardine catches of 0.33 (at a $97 \%$ significance level). The former correlation is therefore non-significant, while the latter is significant, but is only about half as strong as the correlation between Ekman transport and solar activity. We interpret this as the lunar-upwelling correlation being physically less important than the solarupwelling correlation.

\section{DISCUSSION}

Sardine landings show synchronous variations over approximately 25 yr off Japan, California, Peru, and Chile (Kawasaki et al. 1991). According to Chavez et al. (2003), this variability is difficult to explain on the basis of fishing pressure only, and therefore the synchrony must be linked to a large-scale atmospheric or oceanic forcing (Chavez et al. 2003). Our findings suggest that sunspot activity may be the ultimate driving force behind large-scale atmosphere-ocean variability and the regime shifts observed in marine ecological systems (Mann 1993, Chavez et al. 2003).

Solar activity affects $Q_{X} M A$, which is the most important factor controlling recruitment in the study area (Guisande et al. 2004). $Q_{X} \mathrm{MA}$ is higher when the solar cycle is shorter. High $Q_{X} M A$ values enhance recruitment because oceanographic conditions favour egg and larval retention in areas close to the coast, where food availability and therefore sardine catches are higher. However, under the oceanographic conditions that prevail when the solar cycle is longer, eggs and larvae are carried offshore, and sardine catches are therefore lower. However, if the solar cycle is too short, there are only a few years with high $Q_{X} M A$ to trigger sardine population growth.

The close correlation between solar cycle length and temperature at the earth's surface (Friis-Christensen \& Lassen 1991), with the exception of the last 2 decades due to the anthropogenic effect on earth's temperature (Thejll \& Lassen 2000), indicates that when the temperature is higher, $Q_{X} M A$ is onshore. These findings explain why the long-term change in spring coastal upwelling in this area follows the trend of the seasonal temperature anomalies in the northern hemisphere (Guisande et al. 2004), and corroborates the hypothesis that climate warming would lead to a decreased coastal upwelling in March-April, which would benefit recruitment. The remarkable synchrony in interdecadal-scale population variations in widely separated stocks of sardines off Chile, California and south-east Asia (Kawasaki et al. 1991) means that synchrony between catches and solar activity may also be occurring in other upwelling areas.

The effect of solar activity on water transport is probably due to the response of the atmosphere to the sunspot cycle. During a solar maximum, a warming of the summer stratosphere was found to strengthen easterly winds, which penetrate into the equatorial upper troposphere, causing poleward shifts in the positions of the westerly jets (Haig 1996). In this situation, equatorward trade winds bring southern or southwestern winds over the west coast of the Iberian Peninsula and, hence, water transport is onshore (Guisande et al. 2001). This would explain why high temperatures enhance recruitment, and the resulting synchrony between sardine catches and solar activity observed in this study.

Many other important biological processes, e.g. primary production, are affected by upwelling intensity. Therefore, the effect of solar activity on coastal water transport indicates that long-term changes in many biological processes in coastal areas may be regulated by solar activity.

Acknowledgements. We thank the División de Operaciones Pesqueras de la Autoridad Portuaria de Vigo for supplying data on the landings of adult and juvenile sardines. Fruitful discussions with M. Vázquez are acknowledged, and J. MacDonald is thanked for careful reading of this manuscript. This research was supported by project REN2002-04205-C04-01 and the Danish Climate Centre.

\section{LITERATURE CITED}

Chavez FP, Ryan J, Luch-Cota SE, Niquen M (2003) From anchovies to sardines and back: multidecadal change in the Pacific Ocean. Science 299:217-221

Cole J, McGalde J (1998) Clupeid population variability, the environment and satellite imagery in coastal upwelling systems. Rev Fish Biol Fish 8:445-471

Currie RG, Wyatt T, O'Brien DP (1993) Deterministic signals in European fish catches, wine harvests, and sea-level, and further experiments. Int J Climatol 13:665-687

Eddy JA (1976) The Maunder minimum. Science 192: 1189-1202

Friis-Christensen E, Lassen K (1991) Length of solar cycle: an indicator of solar activity closely associated with climate. Science 254:698-700

Gleisner H, Thejll P (2003) Patterns of tropospheric response to solar variability. Geophys Res Lett 30:1711

Guisande C, Cabanas JM, Vergara AR, Riveiro I (2001) Effect of climate on recruitment success of Atlantic Iberian sardine (Sardina pilchardus). Mar Ecol Prog Ser 223:243-250

Guisande C, Vergara AR, Riveiro I, Cabanas JM (2004) Climate change and abundance of the Atlantic Iberian sardine (Sardina pilchardus). Fish Oceanogr 13:91-101 
Haig JD (1996) The impact of solar variability on climate. Science 272:981-984

Kawasaki T, Tanaka S, Toba Y, Tanaguchi A (1991) Longterm variability of pelagic fish populations and their environment. Pergamon Press, Oxford

Kerr RA (1991) Could be the sun be warming the climate. Science 254:652-653

Mann KH (1993) Physical oceanography, food chains, and fish stocks: a review. ICES J Mar Sci 50:105-119

Mann KH, Lazier JRN (1991) Dynamics of marine ecosystems. Blackwell, Oxford

Reid GC (1987) Influence of solar variability on global sea surface temperatures. Nature 329:142-143

Riveiro I, Guisande C, Lloves M, Maneiro I, Cabanas JM (2000) Importance of parental effects in larval survival in Sardina pilchardus. Mar Ecol Prog Ser 205:249-258

Robles R, Porteiro C, Cabanas JM (1992) The stock of Atlanto-

Editorial responsibility: Otto Kinne (Editor),

Oldendorf/Luhe, Germany
Iberian sardine: possible causes of variability. ICES J Mar Sci 195:418-423

Siscoe GL (1978) Solar-terrestrial influences on weather and climate. Nature 276:348-352

Theiler J, Prichard D (1996) Constrained-realization MonteCarlo method for hypothesis testing. Physica D 94:221-235

Thejll P, Lassen K (2000) Solar forcing of the Northern hemisphere land air temperature: New data. J Atmos Sol-Terr Phys 62:1207-1213

Thejll P, Christiansen B, Gleisner H (2003) On correlations between the North Atlantic Oscillation, geopotential heights, and geomagnetic activity. Geophys Res Lett 30:1347

Wilson RC, Hudson HS (1991) The sun's luminosity over a complete solar cycle. Nature 351:42-44

Woodruff SD, Slutz RJ, Jenne RL, Steurer PM (1987) A comprehensive ocean-atmosphere data set. Bull Am Meteorol Soc $68: 1239-1250$

Submitted: August 11, 2003; Accepted: February 3, 2004

Proofs received from author(s): March 8, 2004 